\title{
ERRATUM
}

\section{Enhancement of homocysteine toxicity to insulin-secreting BRIN-BD11 cells in combination with alloxan}

\author{
S M J Scullion, E Gurgul-Convey ${ }^{1}$, M Elsner ${ }^{1}$, S Lenzen ${ }^{1}$, P R Flatt and N H McClenaghan \\ Diabetes Research Group, SAAD Centre for Pharmacy and Diabetes, University of Ulster, Coleraine, Northern Ireland, UK \\ ${ }^{1}$ Hannover Medical School, Institute of Clinical Biochemistry, Hannover, Germany \\ (Correspondence should be addressed to S M Scullion; Email: siobhan.scullion@liv.ac.uk)
}

The journal sincerely apologises for the following errors in this article published in August 2012 issue of the Journal of Endocrinology (vol 214, page 233-238).

The name of the first author should be S M Scullion and not as published.

In the legend to Fig. 1, the levels of significance have been wrongly explained. The levels of significance represented by symbols in the figure are: $\star P<0 \cdot 05$, $\star \star P<0 \cdot 01, \quad \star \star \star P<0 \cdot 0001 \quad$ compared with control. ${ }^{\Delta \Delta} P<0 \cdot 01,{ }^{\Delta \Delta \Delta} P<0 \cdot 001$ compared with $1.1 \mathrm{mM}$ glucose.

In Fig. 2, Panel C, there is an error in the symbol representing the level of significance. The correct figure and legend is given in full below (Fig. 2):
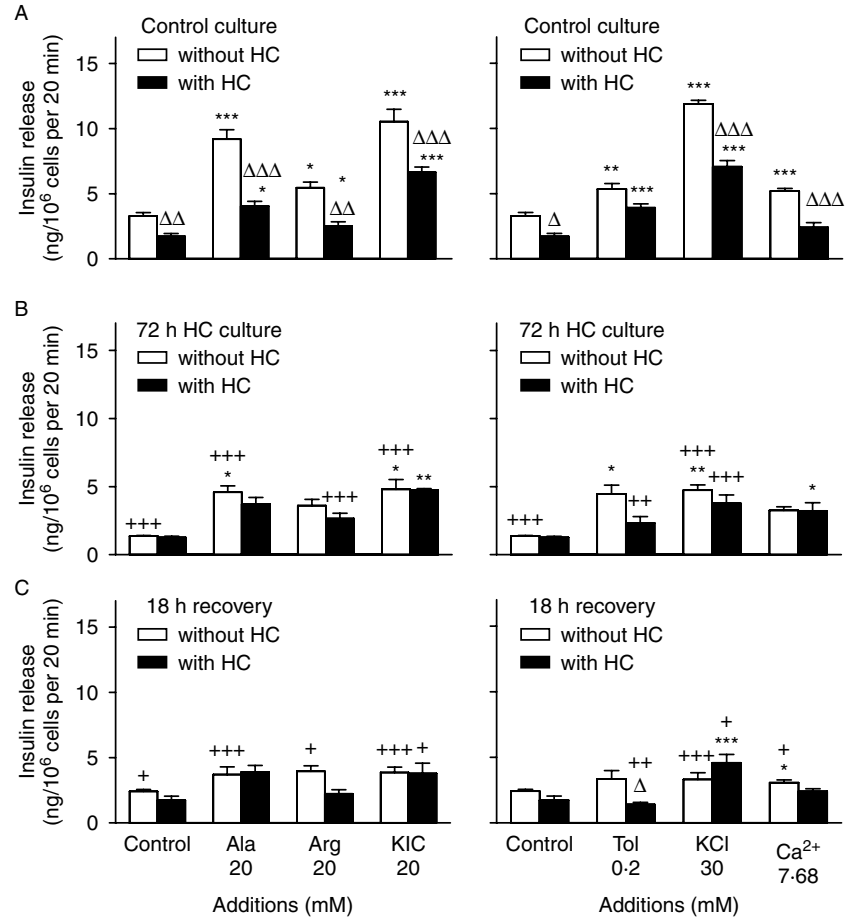

Figure 2 Effects of chronic exposure to homocysteine $(\mathrm{HC})$ on the insulin secretory responses to various secretagogues and the effect of a withdrawal period (18 h). BRIN-BD11 insulin-secreting cells were cultured for $72 \mathrm{~h}$ in the absence (A) or presence (B) of $250 \mu \mathrm{M} \mathrm{HC}$ or with an 18-h recovery period $(\mathrm{C})$ control culture conditions. Following $40 \mathrm{~min}$ preincubation in $1.1 \mathrm{mM}$ glucose, cells were exposed to an acute 20 min incubation with $16.7 \mathrm{mM}$ glucose together with $20 \mathrm{mM}$ alanine (Ala), arginine (Arg) or keto-isocaproic acid (KIC), $200 \mu \mathrm{M}$ tolbutamide (Tol), $30 \mathrm{mM}$ potassium chloride $(\mathrm{KCl})$ or $7.68 \mathrm{mM}$ calcium $\left(\mathrm{Ca}^{2+}\right)$ with or without $250 \mu \mathrm{M} \mathrm{HC}$. Values are mean \pm s.E.M. $(n=6)$. ${ }^{* *} P<0 \cdot 01,{ }^{* * *} P<0 \cdot 001$ compared with control. ${ }^{\Delta \Delta} P<0 \cdot 01,{ }^{\Delta \Delta \Delta} P<0 \cdot 001$ compared with effect without $\mathrm{HC} .{ }^{+} P<0 \cdot 05,{ }^{++} P<0 \cdot 01$, $+++P<0 \cdot 001$ compared with corresponding test agent in control culture. 
In the Funding section the following sentence has been inadvertently left out. S M S was a recipient of a grant in the Erasmus Programme of the European Union.

In the Reference list, Lenzen \& Panten (2008) should not have been included. The correct citation of Patterson et al. (2006b) should be as follows:
Patterson S, Flatt PR \& McClenaghan NH $2006 b$

Homocysteine and other structurally-diverse amino thiols can alter pancreatic $\beta$ cell function without evoking cellular damage. Biochimica et Biophysica Acta 1760 1109-1114. (doi:10.1016/j.bbagen.2006.03.012) 